\title{
SERVICIOS SOCIALES PARA MENORES EN FRANCIA
}

\author{
HORTENSIA REDERO BELLIDO
}

Departamento de Trabajo Social y Servicios Sociales. Universidad de Alicante.

\section{INTRODUCCIÓN}

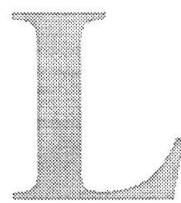

os Servicios sociales dirigidos a los menores y de apoyo a las familias tienen una amplia tradición en Francia. Ya en 1919 Henri Sellier presenta, en su programa electoral para la alcaldía de Suresnes, una propuesta para organizar Servicios de visitadores de la primera infancia, con una orientación médico social, a desarrollar por los municipios ${ }^{1}$.

A lo largo del tiempo han ido modificándose las modalidades de actuación, lo mismo que ha ocurrido en otros países. Así se ha pasado, en determinadas actuaciones, de desarrollar acciones para proteger al menor de su familia a desarrollar un planteamiento preventivo, dando prioridad a mantener al menor en su medio ambiente familiar y a potenciar el mismo, con el fin de proporcionar al menor un entorno adecua$\mathrm{do}^{2}$.

Esta orientación hacia una política familiar se refleja en la existencia de un amplio sistema de preescolar para los niños así como en la atención de día ${ }^{3}$. Esta política permite aumentar la natalidad, facilitar el acceso de los padres al mercado laboral y conseguir el desarrollo de los menores.

La actuación dirigida a los menores está ampliamente supervisada por los poderes públicos con el fin de vigilar su buen desarrollo. Esta atención se desarrolla a través de la ayuda social y la ación social, siendo la primera un derecho subjetivo para el ciudadano y una obligación para el Estado, regulada a través del Código de la Acción Social y

Arnault, A.M.; Bouquet, B. (1991): "Regard socio-historique sur la polyvalence de secteur”, Vie Sociale, $\mathrm{n}^{\circ}$ 9-10, pág. 5.

2 Borgetto, M.; Lafore, R. (1996): Droit de l'aide et de l'action sociales. Montchrestien. París. Págs. 144-145.

3 Ely, P.; Saunders, R. (1993); en Munday, B. (Ed.): European Social Services. European Institute Social Services, University of Kent. Canterbury. Reino Unido. 
la Familia, que sustituye al Código de la Familia y de la Ayuda Social ${ }^{4}$; la acción social se puede desarrollar por iniciativa de las distintas administraciones o por entidades privadas, tiene un carácter más discrecional, ya que puede desarrollar acciones facultativas y algunas otras que están parcialmente determinadas por algún tipo de reglamentación.

\section{DISTRIBUCIÓN DE COMPETENCIAS}

Desde los años 80, Francia es un Estado descentralizado, que implica una distribución de competencias entre el Estado a nivel central y las diferentes colectividades territoriales. En todos los niveles, excepto en los municipios, se encuentra una administración dual. La que representa a la administración central, designada por el gobiemo y la que es elegida por la población en su demarcación territorial. Territorialmente el país se divide en Regiones, relativamente nuevas, Departamentos y Municipios.

Las competencias en materia de protección de los menores se centran fundamentalmente en dos Ministerios: el Ministerio de Empleo y de la Solidaridad y el Ministerio de Justicia, que se ocupa de la protección jurídica de la juventud e interviene en la acción social y la ayuda social con la finalidad de proteger a los menores en situación de riesgo.

Dentro del Ministerio del Empleo y la Solidaridad, en relación con los menores, es importante la Dirección de Acción Social y, dentro de ésta, las Subdirecciones de animación territorial y del trabajo social y la Subdirección de las personas discapacitadas, así mismo es relevante la Dirección Interministerial de la Familia y el/la Ministro/a delegado/a de la familia y la infancia.

De este Ministerio, en materia de Servicios Sociales en sentido amplio, dependen las grandes instituciones, como son la Seguridad Social, los regímenes complementarios, la Mutualidad y la Ayuda social, así como la acción de protección de grupos e individuos: la familia, infancia, discapacitados, $3^{a}$ edad y personas en dificultad ${ }^{5}$. Dentro del sistema de Seguridad Social, la Caja Nacional de la Familia asume determinadas prestaciones dirigidas a las familias para atender a las necesidades de los menores.

Existen otros Ministerios con competencias en materias relacionadas con los niños y jóvenes: el de Educación (asume competencias en

4 Code de l'action sociale et des familles. Journal Officiel de la République Française, $n^{\circ}$ 297. Du 23 décembre 2000. 
materia de salud escolar, becas de enseñanza...), y el de la Juventud y los Deportes que desarrolla actividades socio-educativas y actividades socio-culturales.

El Ministerio regula los tres principales fondos de Seguridad Social y los Servicios Sociales, a través de legislación, políticas, planificación, establece las prestaciones mínimas de carácter universal y el nivel de tasas que los usuarios deben pagar por determinados servicios.

Las Regiones son el siguiente ámbito territorial cuyo representante del poder central es el Prefecto Regional. Tiene su propio personal formado por técnicos y funcionarios que conforman la Dirección Regional de Asuntos Sanitarios y Sociales (DRASS). La administración de los Servicios de Salud depende de este nivel, cuyo papel fundamental es de asesoramiento técnico, apoyo financiero y administrativo, control y evaluación y coordinación de los servicios sociales del siguiente escalón del gobierno, los Departamentos.

Los Departamentos, a través del personal de la Dirección Departamental de Asuntos Sanitarios y Sociales (DDASS), gestiona los servicios de salud y controla los establecimientos sanitarios y sociales. En general, el Prefecto es el responsable de que se ejecuten planes regionales de los servicios sanitarios y sociales, de autorizar la provisión local de esos servicios o de su contratación, de la coordinación financiera y de la inspección. Los servicios fundamentales que dependen de esta Dirección Departamental son los siguientes ${ }^{6}$ :

- Hospitales de corta, media y larga estancia.

- Camas medicalizadas en residencias de ancianos.

- Servicios domiciliarios de enfermería.

- Servicios psiquiátricos.

- Servicios de salud escolar.

- Subsidios por maternidad: expide los certificados de beneficiarios.

- Centros de atención precoz médico-social para niños discapacitados.

- Establecimientos residenciales para menores con grandes discapacidades.

- Talleres de trabajo (CATS) y centros de rehabilitación ocupacional para discapacitados adultos.

5 Borgetto, M.; Lafore, R. (1996): Droit de l'aide et de l'action sociales. París, Montchrestien, pág 72.

6 Ely, P.; Saunders, R. (1993): Ob. cit. págs. 124 y ss. 
- Centros de recepción especial para discapacitados severos.

- Supervisión y financiación del bienestar de los menores que son responsabilidad del estado.

- Proporcionar subsidios a individuos incluidos en proyectos del "Ingreso Mínimo de Inserción" (RMI).

En general dependen de este nivel los centros que desarrollan cuidados dirigidos a la salud.

\subsection{Administración territorial descentralizada}

El nivel más amplio corresponde a las Regiones. El Presidente electo del Consejo Regional puede tener, también, su propio personal de servicios sociales diseñando políticas, planificando y coordinando financieramente los servicios sociales de los Departamentos. En líneas generales las Regiones tienen escasas competencias directas.

Con la descentralización que se produce en el 82, la administración, gestión y prestación de los Servicios Sociales están encomendadas, en su mayoría, a los Departamentos; en concreto, es responsabilidad del Presidente electo del Consejo Departamental. Pueden prestar los servicios directamente o contratarlos con las entidades privadas sin ánimo de lucro.

El 22 de julio de 1983 se votó una ley que delegaba la responsabilidad administrativa de los servicios de protección a los niños a los Departamentos. El gobierno central conserva su poder legislativo y regulador. El Consejo de Departamento se encarga de la organización de los servicios de protección a los niños, la gestión de personal, la creación y financiación de las instituciones y del cobro de los servicios prestados $^{7}$. Todos los Departamentos han desarrollado servicios especializados dirigidos a los menores: Protección Maternal e Infantil, (PMI) y Ayuda Social a la Infancia (ASE).

El presidente del Consejo General es responsable de la provisión, financiación y gestión de subsidios legales y discrecionales de la Ayuda Social, y de los siguientes servicios sociales, los cuales, si no son proporcionados directamente, pueden ser contratados con entidades sin ánimo de lucro:

- Ayuda en el hogar y otros tipos de atención domiciliaria, aparte de los de enfermería, provisión, financiación y gestión de subsidios oficiales. 
- Atención residencial para ancianos y discapacitados menos severos.

- El personal de los Centros Comunitarios de Acción Social, CCAS.

- Servicios de atención de campo, de día y residenciales, para menores (Protección Maternal e Infantil -PMI- Ayuda Social a la Infancia - ASE- y los centros de entidades no lucrativas que pueden estar concertados).

- La creación de los proyectos de RMI.

Así, la prestación de servicios se desarrolla fundamentalmente por el Departamento, aunque la atención primaria se da en los municipios a través de los Centros Comunitarios de Acción Social, CCAS, cuyos trabajadores son contratados por el Departamento. Estos tienen capacidad para adaptar los servicios de acuerdo con las circunstancias demográficas, económicas y políticas. Pueden unirse varios Municipios para desarrollar programas y actividades conjuntamente. Los Municipios tienen un papel muy diverso; disponen de competencias obligatorias y facultativas, higiene publica, servicios de ayuda sanitaria a domicilio, centros de protección maternal e infantil, etc.

Existe por otro lado una amplia tradición en las actuaciones por parte de entidades sin ánimo de lucro, establecidas por la Ley de 1 de julio de 1901, y que desarrollan una amplia labor en el ámbito de los servicios dirigidos a menores y jóvenes. A partir de iniciativas de estas entidades se han desarrollado nuevas modalidades de actuación. No obstante, "algunas de ellas tienden a ganar credibilidad invirtiendo en servicios muy visibles, tales como grandes instituciones, antes que en servicios de atención primaria que proporcionan servicios individualizados". Pueden intervenir tanto en establecimientos como en medio abierto. Sus recursos económicos proceden de diversos ámbitos, entre ellos de la Administración Pública. Tienen que estar acreditadas por los poderes públicos y son objeto de controles regulares.

\section{SERVICIOS SOCIALES PARA MENORES}

La atención dirigida a los menores se puede desarrollar a través de los servicios generales y de servicios específicos para ellos.

\subsection{Servicios de atención primaria polivalente}

En líneas generales los Centros Comunitarios de Acción Social 
(CCAS) son la puerta de entrada a los Servicios Sociales, en la actualidad con tendencia a desarrollar un trabajo de tipo colectivo para dar respuesta a las necesidades de la población. Ofrecen servicios básicos, de carácter polivalente, que proporcionan información, servicios de asesoramiento, tramitación de prestaciones económicas, etc. Tienen encomendada una acción general de prevención y desarrollo social en el Municipio en estrecha colaboración con otras entidades públicas y privadas. «Son los encargados de la coordinación de la acción social en el municipio y, bien llevan directamente el trabajo con familias que tienen menores o ancianos, o son informados de ello. Pueden desarrollar servicios de cuidados de día para menores»?.

El Servicio de Acción Social de los Departamentos contrata trabajadores sociales de dichos Centros (CCAS), los cuales actúan en colaboración con el servicio de Protección Maternal e Infantil (PMI), para proporcionar asesoramiento social e inspección de menores en situación de riesgo, asesoramiento en abortos, y participación en trabajos de información individual o general. Tienen la responsabilidad de hacer el seguimiento de los niños PMI y de los que están atendidos por el ASE (que veremos a continuación), así como de las familias de acogimiento familiar que le son encomendadas.

Las principales misiones y actividades de los Servicios Sociales de atención primaria (Service Social Polyvalente de Secteur) relacionadas con los menores son las siguientes ${ }^{10}$ :

- Acogimiento-orientación.

- Seguimiento social de todas las familias en dificultad, problemas de alojamiento, económicos y financieros, administrativos y jurídicos, de salud, familiares, infancia.

- Alojamiento: acceso al alojamiento, hospedaje de urgencias, mantenimiento en el alojamiento.

- Económicos y financieros: salarios bajos, endeudamiento, desempleo...

- Administrativos y jurídicos: acceso a los derechos, restablecimiento de derechos.

- Salud: acceso a los cuidados, hospitalización, alcoholismo, toxicomanías...

- Familiares: problemas de comunicación, violencia, ruptura, aislamiento, guardia de niños...

9 Ely, P.; Saunders, R. (1993); en Munday, B. (Editor). Ob. cit. pag. 126.

10 Arnauld, A.M. ; Bouquet, B. (1991): "Regard socio-historique sur la polyvalence de secteur". Vie Sociale, nº 9-10. Pág. 15. 
- Infancia: fracaso escolar, absentismo, fuga, delincuencia.

- Seguimiento social de niños PMI (Protección Maternal e Infantil).

- Infancia en peligro, maltrato.

- Mandato ASE: seguimiento de los niños ASE (Ayuda Social a la Infancia) y de las familiar de acogimiento del sector (en algunos Departamentos).

- Aplicación de las nuevas políticas después de 1988:

- El maltrato: Ley de 10-7-1989.

- El sobre-endeudamiento de los particulares y de las familias: Ley de 31-12- 1989.

- Derecho al alojamiento y al seguimiento social: Ley de 31-51990.

\subsection{Servicios específicos de protección social para menores}

Las leyes más importantes en el tema de protección a la infancia son la del 30-6-75; ley sobre la infancia de 6-6-84; la que reforma algunos aspectos de ésta relativas a la ayuda social de 6-2-86; la de 10 de julio de 1989 sobre la prevención de los malos tratos a los menores, la ley de 5 de julio del 96 sobre la adopción y el Código de la Acción Social y la Familia, aprobado en diciembre de $2000^{11}$, que sustituye al código de la Familia y la Ayuda Social que se creó por decreto $\mathrm{n}^{\circ}$ 56-149 de 24 de enero de 1956. Dicho Código pretende recoger todo el conjunto de prestaciones de la ayuda social.

El planteamiento actual en la protección de los menores es que es imprescindible considerar su origen, sus vínculos familiares y su medio cultural, por lo que la actuación debe contemplar estos aspectos. En esta misma línea, se trata de que los niños permanezcan con sus padres, y si no es posible, al menos mantener los lazos entre los menores y sus familias; para ello, se pretende promocionar al máximo el medio familiar, con una voluntad primordialmente educativa. Se trata de implicar al máximo a los padres en la atención de los hijos para que puedan ejercer sus derechos y responsabilidades parentales, animándoles a participar en las decisiones a tomar acerca de sus hijos. Con este fin se crean centros a pequeña escala y se descentralizan los servicios ${ }^{12}$. En

$"$ Ordonnance $n^{\circ} 2000-1249 d u 21$ décembre 2000 relative à la partie Legislative du Code de l'action sociales et des familes. Journal Officiel de la République Française, 23 décembre 2000. Ésta sustituye a determinadas normativas anteriores y quedan integradas en ella.

12 Corbillon, M. (1995): "Francia", en Colton, M.J. y Hellinckx, W. (1995): La atención a la infancia en la Unión Europea. Guia por paises sobre acogimiento familiar y atención residencial. Madrid, Ministerio de Asuntos Sociales, pág.77. 
líneas generales se plantea una gradación de las medidas que van desde la atención en el medio familiar al internamiento en Centros en última instancia. Por otra parte, las circunstancias de los menores asistidos deben ser reevaluadas con regularidad y revisadas al menos una vez al año. Estas bases están contempladas en la Ley sobre los niños de 6 de junio de 1984.

Los principales servicios para familias y menores son responsabilidad del Presidente del Consejo General de los Departamentos, tal como se ha dicho anteriormente. Estos servicios tienen tres componentes principales: el Servicio de Protección Maternal e Infantil, PMI que va dirigido a las madres y los niños de corta edad, con una orientación fundamentalmente de salud. El Servicio de Ayuda Social a la Infancia, ASE. Esto se completa con el Servicio Judicial, Juez de Menores, que dependen del Ministerio de Justicia.

Con fecha 7 de marzo del 2000 se crea la figura del Defensor de los Niños, como autoridad independiente, para defender y promover los derechos del menor.

\subsubsection{El Servicio de Protección Maternal e Infantil (PMI)}

Este servicio fue establecido en 1945 con el objetivo de reducir la mortalidad materna e infantil. Es un servicio no personalizado bajo responsabilidad del Departamento. Desarrolla acciones médico-sociales dirigidas al conjunto de la población, para atender la maternidad y los primeros años de vida de los niños, así como acciones especiales sobre grupos de población desfavorecidos o de ciertos menores.

Potencia las acciones de carácter preventivo, especialmente durante el embarazo, planificación familiar, controles medico-sociales prenatales y post-natales y educación a los futuros padres.

Dirigido directamente a los niños, realiza actuaciones, también de tipo preventivo, durante los seis primeros años de vida del niño, en su propio medio, para lo cual se desarrollan intervenciones en el propio domicilio de puericultura y trabajadores del servicio Social del Departamento.

Por otra parte también presta asesoramiento, orientación profesional y control de los centros o servicios de acogidas de los niños pequeños, como casas nido, guarderías, jardines de infancia, medio escolar, etc.

Son importantes las actuaciones para detectar e intervenir precozmente en el caso de niños con discapacidad. En esta línea actúan los equipos de observación abierta y los Centros de Observación, que tie- 
nen carácter temporal, así como los centros de atención médico-social precoz, que están bajo supervisión e impulso de este servicio.

Con los grupos más vulnerables desarrolla acciones más puntuales para facilitar el mejor uso de los servicios sanitarios y sociales, con acciones preventivas médico sociales con familias de riesgo. Igualmente juega un papel importante para prevenir los malos tratos, a pesar de que esta función, actualmente, es responsabilidad del Servicio de Ayuda Social a la Infancia ${ }^{13}$.

Otro tipo de actividades indirectas son: recopilación de estadísticas en relación a la salud maternal e infantil y expedición de certificados oficiales de embarazo, salud y demás; actividades de educación y promoción de la salud; participación en el adiestramiento de comadronas, visitadores de salud (puericultoras) y enfermeras; vinculación o coordinación entre médicos de familia, hospitales, servicios psiquiátricos infantiles y juveniles, servicios de salud escolar y otros profesionales relevantes ${ }^{14}$.

Este Servicio de Protección Maternal e Infantil está bajo supervisión médica y depende de los servicios sanitarios.

\subsubsection{Servicio de Ayuda Social a la Infancia (ASE)}

Este servicio se plantea para afrontar los riesgos de tipo social que pueden afectar al desarrollo del menor, ya sea por su comportamiento $o$ por dificultades en el medio familiar. En líneas generales, los colectivos de población destinataria de este servicio son los siguientes: los menores sin lazos familiares ("Pupilos del Estado"), los menores víctimas de un medio familiar con carencias y los jóvenes delincuentes. También pueden ser atendidos los jóvenes mayores (18-21 año) que piden protección porque no tienen un medio familiar adecuado. Para ello se plantea una institución de carácter administrativo, el Servicio de Ayuda Social a la Infancia, y otra instancia de tipo jurídico, el Juez de Menores, apoyado por los servicios de Protección Jurídica de la Juventud que dependen del Ministerio de Justicia ${ }^{15}$.

Las líneas de actuación fundamentales se orientan a un trabajo de tipo preventivo, con medidas socio-educativas y de apoyo y promoción de las familias, con el objetivo de mantener al menor con su familia

13 Borgetto, M.; Lafore, R. (1996): Droit de l'aide et de l'action sociale, París, Montchrestien, págs. 145 y ss.

14 Ely, P; Saunders, R. (1993): ob. cit. pág 127.

is Borgetto, M.; Lafore, R. (1996): Droit de l'aide et de l'action sociale, París, Montchrestien, págs. 153 y ss. 
siempre que sea posible o, al menos, no romper los lazos familiares; si la situación es grave y no puede mantenerse en el medio familiar, se deberá hacer cargo del menor, bien a través de los distintos tipos de acogimiento de este servicio o a través de la protección judicial. Las actuaciones se fundamentan en el Código Civil y en el Código de la Acción Social y de la Familia. El propio Código Civil, en su artículo 375, establece que "si la salud, la seguridad o la moralidad de un menor no emancipado está en peligro, o si las condiciones de su educación están gravemente comprometidas, las medidas de asistencia educativa pueden ser ordenadas por la justicia a petición del padre y la madre conjuntamente, o de uno de ellos, del guardián o tutor, del menor mismo o del Ministerio Público. El Juez puede actuar de oficio a título excepcional".

El Servicio de Ayuda Social a la Infancia es el responsable de la prevención del maltrato y de la protección de los menores; actúa en colaboración con los otros servicios, PMI, Acción Social y los Servicios del Estado, especialmente los de justicia, educación y salud. Sus servicios están a disposición de todas las familias y de todos los menores y jóvenes adultos, hasta la edad de 21 años, que tengan circunstancias que afecten a su estabilidad.

El planteamiento de la actuación es doble: por una parte con acciones sobre el menor y el núcleo familiar para que las familias asuman sus responsabilidades educativas y de este modo prevenir las posibles situaciones de riesgo. Así viene establecido en el Código de la Acción Social y de la Familia en su artículo L 221-1-1": "Aportar apoyo material, educativo y psicológico a los menores, su familia, a los menores emancipados y a los mayores de edad menores de 21 años enfrentados a dificultades sociales susceptibles de comprometer gravemente su equilibrio". Para esta actuación se proporcionan tanto medidas de apoyo en el hogar (por ejemplo, la ayuda a domicilio, recogida en el mismo Código), como ayudas económicas.

Las ayudas de apoyo en el hogar que se establecen son las siguientes:

- $\mathrm{Art}^{\circ}$. L 222-2: la ayuda a domicilio es atribuida sobre su demanda, o con su acuerdo, a la madre, al padre, o en su defecto a la persona que asume la carga efectiva del menor, cuando la salud de aquél, su seguridad, su mantenimiento o su educación lo exige y, para las prestaciones en especie, cuando el demandante no disponga de recursos suficientes.

- Es otorgada a las mujeres embarazadas enfrentadas a dificultades médicas o sociales y financieras mientras su salud o la del menor lo exige. 
- Puede contribuir a prevenir una interrupción voluntaria del embarazo.

- Puede ser concedida a los menores emancipados y a los mayores de edad menores de 21 años, enfrentados a dificultades sociales.

- Art $^{\circ}$ L 222-3: la ayuda a domicilio comporta, conjunta o separadamente:

- Intervención de un/una técnico/a de intervención social y familiar o de una ayuda al hogar.

- La intervención de un servicio de acción educativa.

- El pago de ayudas económicas efectuadas ya sea bajo la forma de ayudas excepcionales, asignación mensual, a título definitivo o bajo la condición de reintegro, eventualmente expedida en especie.

- $\mathrm{Art}^{\circ} \mathrm{L} 222-4$ : El socorro y la asignación mensual de ayuda a domicilio no se pueden ceder y son inembargables. Algunas veces, a petición del beneficiario, pueden ser otorgadas a toda persona temporalmente encargada del menor.

Cuando es nombrado un tutor de las prestaciones sociales, recibe de pleno derecho las asignaciones mensuales de ayuda a domicilio.

Por otra parte, con actuaciones preventivas, de naturaleza colectiva, en el medio más amplio donde se desenvuelven los menores y adolescentes, no solamente en el medio familiar. Estas acciones se desarrollan en los barrios, vecindario, extrarradio, con grupos de menores y adolescentes, y están dirigidas a conseguir la reinserción familiar y social. Es un trabajo de tipo comunitario orientado a que los propios interesados participen activamente, tanto para identificar sus necesidades como para desarrollar y demandar servicios. Se llevan a cabo distintos tipos de actuaciones, algunas de ellas de prevención especializadas, acciones de animación, organización de clubs, etc. desarrollados por equipos de prevención socio-educativos. Esta actuación puede ser llevada acabo tanto por el Servicio de ayuda Social a la Infancia como por los Servicios Sociales de los Centros Comunitarios de Acción Social o por entidades sin ánimo de lucro. Generalmente todas ellas trabajan en colaboración.

- $\operatorname{Art}^{\circ}$ L 221-2-3: Organizar en los lugares donde se manifiestan los riesgos de inadaptación social, las acciones colectivas con vistas a prevenir la marginalización y a facilitar la inserción o la promoción social de los jóvenes y de las familias. 
Otra de las misiones del Servicio es la prevención del abandono del menor. En esto se plantean dos posibilidades: o bien el menor, por dificultades temporales, no puede permanecer con la familia y, a petición de ésta, es acogido temporalmente; o bien cuando hay riesgo de maltrato, privación de los cuidados que necesita, o corre un grave riesgo de caer en delincuencia; en estos casos se recurre al Juez de Menores que es quien tiene la competencia para tomar otro tipo de decisión, como puede ser quitar la tutela a los padres u otro tipo de medidas necesarias. Igualmente pueden ser acogidas las madres con hijos pequeños que tienen dificultades y los jóvenes más mayores o emancipados (18-21 años).

- Art $^{\circ}$ 222-5: Serán tomadas a cargo por el servicio de Ayuda Social a la Infancia sobre la decisión del Presidente del Consejo General:

- Los menores que no pueden provisionalmente ser mantenidos en su lugar de vida habitual.

- Los pupilos del Estado remitidos al servicio en las condiciones previstas en Ios artículos L 224-4, L 224-5, L 224-6 y L 224-8 ${ }^{16}$.

- Los menores confiados al servicio en aplicación del artículo 375 3 del Código Civil, de los artículos 375-5, 377, 377-1, 380, 433 del mismo código o del $4^{\circ}$ del artículo 10 y del $4^{\circ}$ del artículo 15 de la ordenanza ${ }^{\circ} 45-174$ de febrero de 1945 relativa a la infancia delincuente.

- Las mujeres embarazadas y las madres aisladas con sus hijos de menos de 3 años que tengan necesidades de un apoyo material y psicológico.

- Pueden ser igualmente tomados a cargo a tí́tulo temporal por el servicio encargado de la ayuda social a la infancia, los menores emancipados y los mayores de edad menores de 21 años que tengan dificultades de inserción social, faltos de recursos o de apoyo familiar suficiente.

Para desarrollar esta función el Departamento debe organizar territorialmente los medios para hacerse cargo y alojar a estos menores. Estos medios comportan, especialmente, posibilidades de acogimiento de urgencias, así como estructuras de acogimiento para las mujeres embarazadas y las madres con sus hijos, como son los Hogares maternales, Centros de alojamiento y de reinserción social, y Residencias Sociales para acoger a mujeres y madres con hijos víctimas de los malos tratos. Estos servicios pueden ser del propio Departamento, 
de otras circunscripciones territoriales o bien pueden estar concertados con entidades privadas, cuyos establecimientos tienen que estar habilitados por los organismos públicos.

Para la prevención de los malos tratos y la atención a los niños maltratados existe un servicio telefónico de urgencias gratuito, que responde en todo momento a las peticiones de información o consejo sobre situaciones de malos tratos o sospecha de ellos. El nuevo código de la Acción Social y de la familia establece actuaciones de información y sensibilización a la población; recoger información acerca de los niños maltratados. En el caso de sospecha de malos tratos y falta de cooperación por parte de los padres, se puede remitir a la autoridad judicial ( $\operatorname{art}^{\circ}$ 226-4), y el Juez de Menores y el Presidente del Consejo General departamental deberán establecer una protección conjunta del menor.

Entre las intervenciones para el acogimiento que desarrolla el servicio están las Familias de acogida, que sustituyen a la familia de origen; en este caso los padres tienen que dar el consentimiento. Si hay dificultades u obstáculos importantes por parte de los padres biológicos, se puede considerar como una razón para que el menor ingrese en un centro de acogida temporal. También pueden ser acogidos en Hogares de colocación familiar especializada con Asistentes maternales remuneradas, que acogen en su domicilio a menores, como máximo pueden acoger a tres menores; tiene que estar reconocida por los órganos administrativos competentes del Departamento. El Servicio de Ayuda Social a la Infancia es el responsable de seleccionar y asesorar a los padres de acogida.

El servicio proporciona una gama muy amplia de centros y residencias de menores, de titularidad pública o de entidades privadas sin ánimo de lucro, como son las siguientes:

- Hogares para niños: pueden acoger a los menores temporalmente o de forma continuada o bien preparar a los niños para acogimiento familiar. Debe haber al menos uno en cada Departamento.

- Centros asistenciales de día.

- Hogares maternales.

- Centros judiciales de protección de la juventud, dependientes de la Protección Judicial de los Menores.

- Internados.

- Hostales para trabajadores que acogen a jóvenes mayores, entre 18 y 21 años.

- Instituciones para menores con discapacidad.

- Aldeas para niños y familias de acogida. 
La financiación de estos centros depende de la «categoría» de menores: los denominados Pupilos del Estado, que carecen de contacto con los padres; los jóvenes mayores que son remitidos por los jueces; o aquellos que no son responsabilidad de ningún Departamento, niños extranjeros, se financian por el Estado, ya que son de responsabilidad nacional; para el resto de los menores, los padres deben colaborar de acuerdo con los medios que tienen y el resto lo aporta el Departamento.

El Servicio tiene que controlar a las personas físicas o morales a las que ha confiado los menores con vistas a asegurar las condiciones materiales y morales de su colocación, tal como establece el Código de la Acción Social y de la Familia.

Los niños en situación de abandono, Pupilos del Estado, pueden ser entregados en adopción que puede ser simple y plena; ésta última implica para los adoptados las mismas obligaciones, con respecto a los padres adoptantes, que los hijos biológicos, prestar alimentos y socorrerlos en caso necesario.

"La responsabilidad de la supervisión de los menores en su propio domicilio puede, por tanto, ser ejercida por un trabajador del PMI, el CCAS, el ASE, el sector asociativo, o la Justicia (ver más adelante), o por una combinación de algunos de ellos, dependiendo de los acuerdos a nivel local, de la disponibilidad de recursos y de las circunstancias de cada caso. La colaboración es más fácil en municipios grandes con centros que atienden a un gran volumen de población donde el PMI, CCAS y ASE, a pesar de su diferente relación con los servicios médicos, el municipio y el departamento, pueden prestar sus servicios en el mismo edificio, que en los municipios rurales, en los que los CCAS sólo abren durante un tiempo limitado a la semana, con las consiguientes demoras en la preparación de expedientes para ser remitidos a la institución adecuada ${ }^{17}$.

\subsubsection{Protección Jurídica del Menor: Servicios del Ministerio de Justicia}

Desde 1945, se reconoce que la Justicia aplicable a los adultos no se puede adaptar a los menores. La Ordenanza del 2 de febrero de 1945 es el texto fundador de la justicia juvenil. Los niños y los adolescentes de menos de 18 años tienen que tener su propia justicia.

La protección jurídica de los niños corresponde al Ministerio de Justicia, tal como recoge el artículo 375 del Código Civil, "los jueces están 
facultados para intervenir en la vida de los jóvenes a fin de prevenir conductas delictivas". Las medidas adoptadas son decisión del Juez, pero la ejecución corresponde a los Departamentos.

En la ley se plantea asegurar la protección de los menores cuando las situaciones familiares ponen en peligro al menor (niños maltratados, incesto, prostitución, etc.), cuando hay dificultades en el medio familiar (conflictos familiares, fugas, escasa presencia de los padres) y fallan las medidas preventivas. Por otro lado también tiene la función de sancionar los actos de delincuencia de los menores (robo, vandalismo, droga, etc.).

De acuerdo con esto, los jóvenes de los que se hace cargo la Justicia de los menores son: los jóvenes en peligro, los jóvenes delincuentes y los jóvenes mayores (18-21 años).

En síntesis las dos misiones fundamentales son: proteger a los jóvenes en peligro, que se considera lo esencial de su actividad, y juzgar a los menores delincuentes.

Los Servicios de Acción Social Comunitaria, el Servicio de Ayuda Social a la Infancia y el Servicio de Protección Maternal e Infantil del Departamento, así como las entidades sin ánimo de lucro actúan en colaboración y con el consentimiento de los propios padres. En caso de que este sistema falle se deben derivar los casos al Juez de Menores para que tome una decisión.

Los casos pueden llegar al Juez remitidos por cualquier profesional o autoridad de los distintos servicios. "Es derecho de todo ciudadano, adulto o menor, requerir la intervención del juez si son conscientes de que un menor está en peligro" o si "las circunstancias de su educación se están viendo seriamente comprometidas". "La Ley de 15 de junio de 1971 obliga a cualquiera no ligado a un código de secreto profesional a notificar a las autoridades cualquier caso de maltrato o negligencia a un menor por debajo de los 15 años que conozcan". "La Ley también releva de cualquier penalización a toda persona obligada por un código de confidencialidad si la rompe informando a las autoridades. La única excepción al derecho general de audiencia con el juez es que la policía sólo puede remitir temas al juez a través del fiscal público. Este es el camino a través del cual los delincuentes llegan al juez, pero también en casos de emergencia por abuso o negligencia, ya que el fiscal ofrece un servicio de 24 horas y recibe derivaciones solicitando protección judicial que ocurren fuera de los horarios de trabajo. En todo caso, los menores, tanto si están en casa como si están bajo la protección pública, pueden solicitar del juez ayuda por ellos mismos o a través de otros, de tal manera que el juez actúa como un defensor de menores" 18 . 
De acuerdo con la circunstancia por la que llega el menor al Juez de menores puede ser necesario un procedimiento civil o penal. En síntesis, corresponde el civil cuando el menor es el perjudicado y no hay ningún tipo de falta por parte de éste, y el procedimiento penal cuando el menor ha cometido alguna falta, delito o crimen. En cualquiera de los casos siempre se trata de potenciar las medidas educativas.

En los casos en que es el menor el perjudicado por abandono, negligencia, malos tratos, etc. puede tomar distintas opciones:

1. Sin ruptura con el medio familiar: se potencia la asistencia educativa, y una solución de conciliación y de acompañamiento para evitar el efecto traumático de una ruptura con el medio familiar, tal como recoge el Código Civil en su artículo 375.2, por lo que puede establecer distintos tipos de medidas socio-educativas. Por una parte puede "designar a una persona cualificada, a un servicio de observación, de educación o reeducación en medio abierto y para dar ayuda y consejo a la familia con el fin de superar las dificultades materiales o morales que ella encuentra. Esta persona o estos Servicios tienen que responsabilizarse del seguimiento del desarrollo del menor y dar un informe periódicamente al Juez". En este caso el menor se mantiene en el hogar familiar para seguir con sus actividades en el medio habitual.

Por otra parte, el Juez puede tomar la decisión de retirarlo del medio familiar, y en este caso puede "confiarlo al padre o madre que no tuviera la guardia del menor, a otro miembro de la familia o a un tercero digno de confianza, a un servicio o a un establecimiento sanitario o educativo, ordinario o especializado, o bien al servicio Departamental de Ayuda Social a la Infancia" ( $\operatorname{art}^{\circ} 375.3$ del Código Civil). En cualquier caso, de modo provisional, el Juez puede ordenar que el menor sea remitido a un centro de acogida o de observación, a un centro de alojamiento familiar especializado, temporalmente o a más largo plazo.

2. Cuando el menor ha cometido alguna falta, delito o crimen, tiene que presentarse ante la Justicia penal de los menores.

En esta situación, dependiendo de la gravedad del delito y de la edad del menor, éste puede tener que comparecer ante distintos tribunales, Tribunal para menores (Juez de Menores y 2 asesores, en el caso de los menores de 16 años que han cometido algún delito), Audiencia de Menores ( 3 Magistrados, presididos por el Juez de Menores y un jurado de 9 miembros, para los mayores de 16 años que han cometido crímenes).

is Ely, P.; Saunders, R. (1993): Ob. cit. págs 130-131. 
En la justicia penal de los menores se aplican unos principios que lo diferencian de la justicia aplicada a los adultos ${ }^{19}$.

- Las jurisdicciones para menores pronuncian prioritariamente medidas de protección, de asistencia, de vigilancia y de educación (la medida educativa debe primar sobre la sanción penal).

- Los menores de 13 años no pueden ser sancionados penalmente; sólo se pueden pronunciar medidas educativas.

- Los menores de más de 13 años se benefician de un régimen de responsabilidad atenuado y de disminución de la pena.

- Los menores se benefician de reglas de procedimiento particulares adaptadas a su edad (libertad vigilada, detención provisional).

Este planteamiento se basa en que las infracciones penales se pueden considerar un síntoma de inadaptación ${ }^{20}$. No obstante, en los casos graves de delincuencia de los mayores de 16 años, se pueden dictar medidas más contundentes y de mayor control, incluso verdaderas sanciones penales.

De acuerdo con estas bases también en estos casos se priorizan las medidas educativas y el Juez puede adoptar las mismas que en los procedimientos anteriores. Pero, de acuerdo con las circunstancias, puede remitirlos a un establecimiento de educación o de formación profesional o al ASE. Algunos menores delincuentes precisan centros de una mayor especialización.

La Protección Judicial del Menor dispone de sus propios profesionales especializados así como de estructuras específicas y de personal para desarrollar su función con los menores: hay servicios de investigación que ayudan a la decisión del juez y que llevan a cabo medidas provisionales de corta duración, de 3 a 6 meses; el Servicio de Educación Vigilada que asesora y supervisa las situaciones familiares siguiendo las indicaciones del Juez, y que tienen a jóvenes bajo su cuidado; Servicios educativos en medio abierto y establecimientos de tipo penitenciario como casas de arresto, centros de detención, centros de semilibertad.

Además de estos servicios el Juez puede asesorarse de los organismos y profesionales que considere convenientes y remitir a los menores a los servicios Departamentales de Ayuda Social a la Infancia o a los servicios sociales polivalentes.

20 Borgetto, M.; Lafore, R. (1996): Ob. cit. pág. I6I. 
El Juez, en su obligación de salvaguardar los derechos del menor, tiene el deber de intervenir en cualquier organismo público o privado si dichos derechos son lesionados. En cualquier caso el juez puede revisar sus decisiones de acuerdo con la evolución del menor y la situación de su entorno.

Las instituciones, públicas o privadas, que acogen a menores por decisión judicial, son inspeccionadas y autorizadas por el Ministerio de Justicia. En estas instituciones pueden estar tanto menores por decisión judicial como por decisión del Servicio de Ayuda Social a la Infancia. Los recursos que se aplican a los menores son independientes de la vía por la que han llegado a la protección pública.

El juez puede también tomar decisiones acerca del uso de las prestaciones familiares otorgadas en función de los hijos, que se pueden otorgar al tutor del menor.

\subsection{Servicios para menores con discapacidad}

La ley de 1975 considera que los menores con discapacidad deben acceder a las mismas instituciones y prestaciones que el resto de los menores, pero existen una serie de prestaciones específicas: prestaciones para la obligación de educación y subsidio de educación especial hacia su familia ${ }^{21}$.

Tal como establece el artículo 4 de la Ley de 1975 y el Código de la Acción Social y de la Familia, recientemente aprobado, los menores con discapacidad están sometidos a la obligación de la educación y deben ser escolarizados en el medio ordinario, siempre que sus condiciones se lo permitan, con el objetivo de favorecer su integración, desarrollar su personalidad, ayudar a aceptar sus diferencias, favorecer su autonomía y facilitar el acceso al mundo del trabajo y de la participación social. En el medio ordinario se ofrecen medidas de acompañamiento para la mejor integración en el medio escolar, con apoyo de equipos especializados o clases de integración escolar especializada $u$ otras similares. La integración en la enseñanza ordinaria requiere que el menor pueda desarrollar un mínimo de comunicación con su entorno. Si esto no fuera posible se puede escolarizar en medio especializado. Para esto existen diversos tipos de centro, dependiendo de la discapacidad $^{22}$ :

- Centros de acción médico-social precoz, (CAMSP) con la finalidad de lograr la educación del menor y proporcionar entrena-

2 Borgetto, M.; Lafore, R. (1996): Ob. cit. pág. 231.

22 Ely, P; Saunders, R. (1993): Ob. cit. pág. 137. Y Borgetto, M.; Lafore, R. (1996): Ob. cit. pág. 233 . 
miento a las familias para una mejor atención.

- Institutos de Educación Sensorial, dirigidos a los menores con discapacidad sensorial.

- Institutos de Educación Motriz, para los menores con discapacidad motora.

- Instituto Médico-Pedagógicos (IMP) para los menores con dificultades de aprendizaje, con edades comprendidas entre 3 y 16 años.

- Centros Médico-Psico-Pedagógicos,(CMPP) para los menores con dificultades de comportamiento.

- Institutos Medico Educativos (IME), para los afectados de discapacidad mental.

- Institutos Médico profesionales (IMPRO), dirigidos a los que tienen entre 16 y 20 años para prepararlos profesionalmente.

La valoración de las discapacidades se hace por la COTOREP (Comisión Técnica de Orientación y Clasificación Profesional), pero corresponde a la Comisión Departamental de Educación Especializada (CDES) el papel fundamental en cuanto a la orientación sobre los menores con discapacidad, la designación del tipo de centro o servicio que precisa, y las ayudas económicas necesarias para que el afectado reciba la atención adecuada; se encarga, así mismo, del seguimiento de la integración del menor. Solamente se encarga de los afectados por discapacidad física, sensorial y mental.

Existe una prestación económica (Allocation d'éducation spéciale, AES) para que las familias puedan hacer frente a los costes extras de la educación de un menor afectado de discapacidad, mayor de 6 años; es aportada por la Caja Nacional del Seguro Familiar de la Seguridad Social. Para los casos más graves que precisan de una tercera persona para su cuidado, de acuerdo con la valoración de la CDES, existe un complemento, que puede ser distinto según los cuidados que precise:

- menores que precisan cuidados diarios discontinuos,

- niños que necesitan cuidados diarios continuos,

- niños que requieren de cuidados continuos altamente especializados.

Los Servicios para discapacitados pueden ser ofrecidos por Educación, por el Servicio de Salud, o conjuntamente, dependiendo de las circunstancias y de la atención a desarrollar, pero la responsabilidad financiera puede ser de distintos organismos. Aquellos que no están asegurados pueden percibir la prestación económica por el Servicio de Ayuda Social a la Infancia. 
Actualmente hay una preocupación por la atención a los polidiscapacitados, tratando de dar una respuesta a todas las necesidades que tiene el menor, tanto afectivas, pedagógicas, relacionales, como terapeúticas y por una mayor implicación de los padres en la educación especializada.

\section{OTRAS ACCIONES Y PRESTACIONES PARA EL MENOR O LA FAMILIA}

Además de los servicios que se han visto a lo largo de este texto, existen otras actuaciones facultativas desarrolladas por los Municipios, Departamentos y por las distintas entidades no lucrativas, que responden a las distintas circunstancias sociales y económicas así como al grado de iniciativa y capacidad desarrollada. En ellas se observa una gran preocupación por abordar los temas de los menores y jóvenes en situación de riesgo y desarrollar actuaciones dirigida al tiempo libre y el ocio, como medio de lograr la integración social y prevenir la delincuencia. Se trata de potenciar a los propios interesados para que actúen con sus propios proyectos y se impliquen directamente en su ejecución. Es especialmente importante para los grupos de jóvenes con mayor riesgo de marginación, así como para jóvenes de grupos minoritarios de otros países.

Las prestaciones económicas a las familias con menores pueden ser de distinta índole. Unas de carácter universal, y otras por insuficiencia de recursos de la familia, que son una ayuda suplementaria: prestaciones de ayuda social y prestaciones familiares.

La Seguridad Social a través de la Caja Nacional del Seguro Familiar (CNAF) y también por la Mutualidad Agraria, aporta el ingreso mínimo familiar para las familias con hijos menores de tres años, a las familias que tengan al menos tres hijos por encima de los tres años, y para aquellos que tengan a su cuidado, al menos, a tres niños. Ayuda a los padres que interrumpen su trabajo por el nacimiento, adopción o por el cuidado de un tercer hijo o más. Hay prestaciones económicas para menores huérfanos, familias monoparentales y familias con menores con discapacidad (citada anteriormente). Otro tipo de subvenciones a familias jóvenes para afrontar los costes de los intereses bancarios y por vivienda para las familias que tienen menores o personas mayores a su cuidado que vivan con ellas. 


\section{BIBLIOGRAFÍA}

ARNAULT, A.M.; BOUQUET, B. (1991): "Regard socio-historique sur la polyvalence de secteur", Vie Sociale, $\mathrm{n}^{\circ}$ 9-10.

BORGETTO, M.; LAFORE, R. (1996): Droit de l'aide et de l'action sociales. París, Montchrestein.

CENTRE POUR LA RECHERCHE ET L'INNOVATION DANS L'ENSEIGNEMENT: (1996). Integrer les services pour les enfants à risque. Danemark, France, Pays-Bas, Royanne-Uni (Angleterre et pays de Galles) et Suède. OCDE.

CODE DE L'ACTION SOCIALE ET DE LA FAMILE. Journal Officiel de la République Française. 23 décembre 2000.

COLTON, M.J.; HELLINCKX, W. (1995): La atención a la infancia en la Unión Europea. Guía por países sobre acogimiento familiar y atención residencial. Madrid, Ministerio de Asuntos Sociales.

CONSEIL TECNIQUE DES CLUBS ET ÉQUIPES DE PRÉVENTION SPÉCIALISÉE. (1996): La violence des jeunes en milieu urbain. París. Direction de l'Action Sociales.

FAUQUEMBERG, A. (1999): "Temporalités des trajectoires rellationnelles des parents d'enfants placés”. Vie Sociale, n 5, págs. 35-42.

LAHEURTE, P. (1998): "Maternités socialement précoces: un foyer de jeunes filles à I"épreuve de ses objectifs". Vie Sociale, nº, págs. 71-86,

MAUGER, G.: Les jeunes en France. Etat des recherches. París. La documentation Française. Ministère de Ia Jeunesse et des Sports.

MUNDAY, B. (1993): European Social Services. European Institute of Social Services. University of Kent. Canterbury. 